\title{
Developing Key Performance Indicators for Shipbuilding PLM
}

\author{
Sehyun Myung \\ Youngsan University, Yangsan, Korea \\ msheysu.ac.kr
}

\begin{abstract}
This paper describes how to develop key performance indicators (KPI) for shipbuilding PLM. The decision maker can evaluate product development performance and risk by analyzing key performance indicators (KPI). Establishment of KPIs in the shipbuilding industry involves analyzing existing performance indicators and benchmarking other industry's performance indicators. In this paper, the KPIs are classified into three categories: project management viewpoint, business unit viewpoint, and enterprise management viewpoint.
\end{abstract}

Keywords: Shipbuilding, PLM, Performance management, Key performance indicators, Big data Analysis

\section{Introduction}

Product Lifecycle Management ("PLM", henceforth) is started from CAD and CAD data management, and evolved to enterprise IT system which includes project management, requirement management, portfolio management, quality management, R\&D strategy management, technical asset management, performance management and so on. PLM has been adopted gradually by industry from aerospace to shipbuilding, automotive, electronics and heavy industry. PLM can be a key innovation tool to be a great company, and PLM system regarded as one of major ICT solutions with ERP and SCM for the enterprise company. This paper describes how to develop KPI for shipbuilding PLM. The decision maker can evaluate product development performance and risk by analyzing KPI.

The performance indicator (PI) is an index that measures the extent to which an organization achieves its goals. In business informatics, KPIs represent current business conditions and are used to predict what will happen in the future. Real-time monitoring of KPI is called business activity monitoring. In addition, KPI provide layer-bylayer visibility and enable quick decision support. The KPI building and management process is conducted in the order of information provision, cause analysis, decision making and direction, and change management.

Establishment of KPI in shipbuilding industry involves analysis of existing KPI and benchmarking of KPI of other industries. The derived KPI can be used for product development performance evaluation and risk assessment services using Big Data

adfa, p. 1, 2011.

(C) Springer-Verlag Berlin Heidelberg 2011 
analysis methodology. In this paper, the KPIs are classified into three categories: project management viewpoint, business unit viewpoint, and enterprise management viewpoint.

\section{$2 \quad$ Related Research}

The start of KPI application is 'management by objectives' advocated by Peter Drucker. Peter Drucker insisted that in order for an enterprise company to achieve performance, each task should focus on the enterprise-wide goals. The goal here is to be concrete, measurable, achievable, realistic and time-sensitive [1].

Studies on KPIs have been conducted in various ways. Issa et al. [2] described environmental performance indicators (EPI) related to products for environmentally friendly design in manufacturing, and derived 261 EPIs from 500 indicators.

Rodrigues et al. [3] categorized the product development process into seven stages: product strategy planning, informational design, conceptual design, detailed design, production preparation, production launch, product accomplishment and monitoring, and derived 787 KPIs in product development.

Alemanni et al. [4] studied KPI for the benefits of introducing PLM systems to the aviation industry and derived 54 KPIs for quality, time, cost, infrastructure, and communication.

Myung [5] described Samsung Electronics' implementation of enterprise PLM and referred to performance management using KPI as a module of PLM system.

Folan et al. [6] described that performance management evolved from the recommendation of performance management to the establishment of performance management framework, the establishment of performance management system, and the management of performance between organizations.

\section{Development of KPIs}

\subsection{Collect and Analyze Performance Indicators}

Hundreds of PIs are already in use in the shipbuilding industry. The PI is the kind of artifact that changes from time to time. Depending on the business environment, the calculation formula and the upper / lower thresholds are different.

This research investigates and evaluates PIs of shipbuilding design PLM and nonshipbuilding PLM and derives KPIs that can be applied to the shipbuilding field.

PI includes name, definition and purpose, process to which KPI belongs, performance measurement / registration cycle, calculation method, calculation formula, evaluation unit, threshold and target value, quantitative evaluation / qualification evaluation, application department and others.

Figure 1 shows the general PI derivation process. After the goal setting, the PI is determined after the investigation, and then the threshold value and the target value of the PI are determined, and the result is analyzed. 


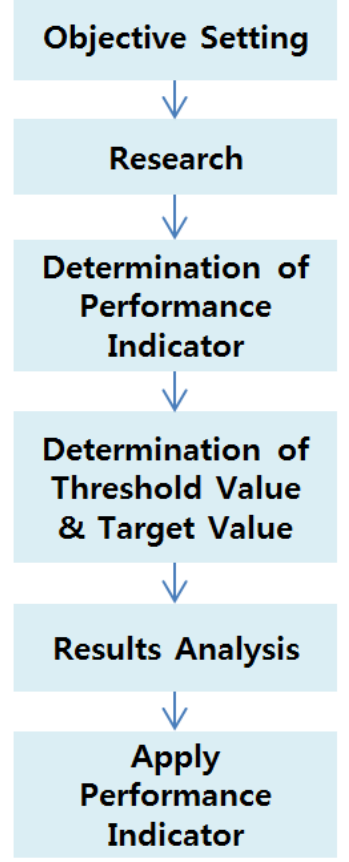

Fig. 1. Performance Indicator definition process

Figure 2 shows the KPI derivation method for shipbuilding PLM. After investigating the KPIs in the shipbuilding and non-shipbuilding industry, KPIs are derived from the viewpoints of 3 categories in the shipbuilding PLM. The calculation formula is determined and the KPI contents are checked through the module for visualization.

54 KPIs of three companies in the shipbuilding industry were collected, including 18 KPIs from company A, 28 KPIS from company B, and 8 KPIS from company C. The major categories of shipbuilding KPIs can be classified into design, procurement, and manufacturing by category, and they can be classified into strategic KPI, intrinsic KPI, and cost KPI by characteristic.

In the non-shipbuilding industry, $220 \mathrm{KPIs}, 46 \mathrm{KPIs}$ in the electronics industry and 38 KPIs in the construction/plant industry were collected and analyzed.

Performance management based on KPI in mass production industry is centered on EQCD (efficiency, quality, cost, delivery) during development and centered on PQCD (productivity, quality, cost, delivery) during production.

At the time of development, performance management is carried out focusing on development efficiency, quality, material cost, and delivery. In production, performance management is carried out focusing on productivity, quality, cost, and delivery. 


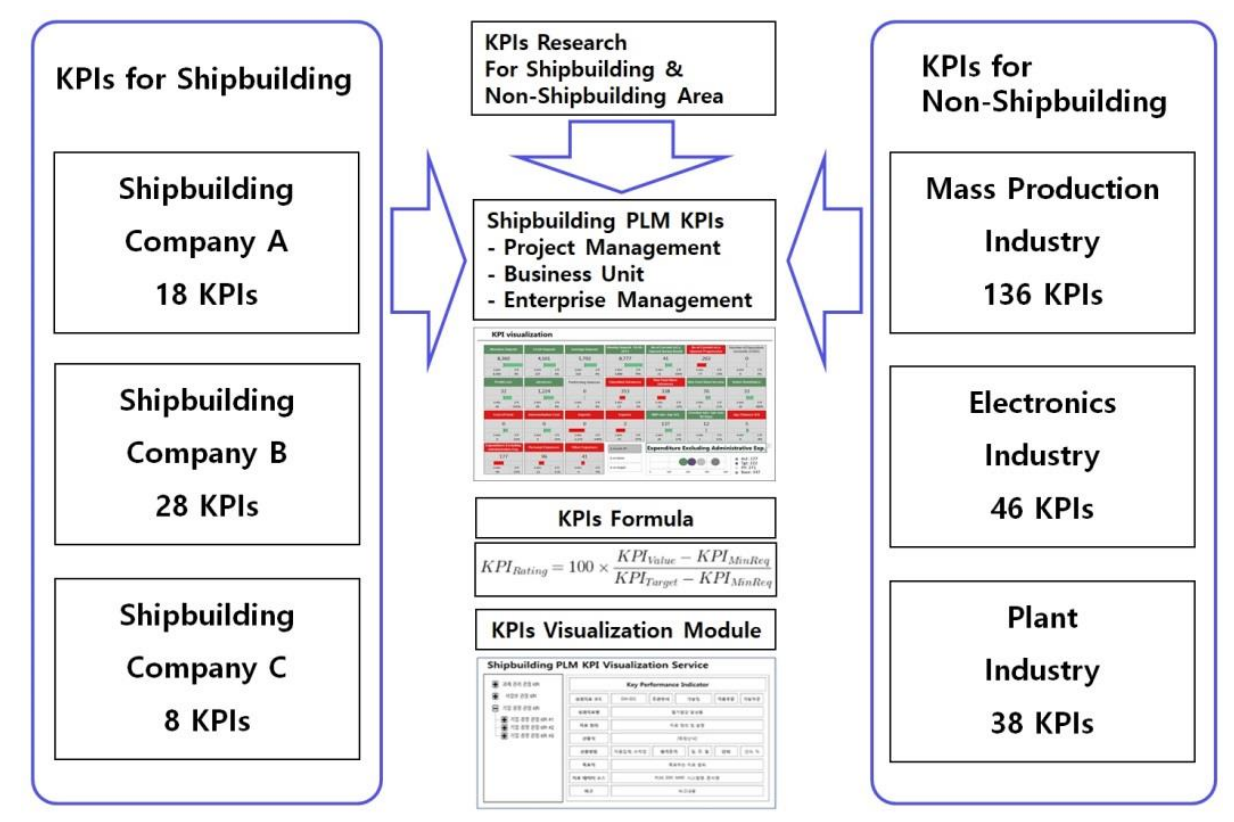

Fig. 2. KPI development process of shipbuilding PLM

However, if we look closely, efficiency, delivery, and quality can all be converted into cost. The KPI of the mass-production industry is different from the shipbuilding industry, which is an order-taking business. In the shipbuilding industry, which is a contractor, performance management is carried out on the total volume of a vessel that are constructed without taking into consideration the material cost considering the cost per production unit.

\subsection{Developing KPIs}

In this research, KPIs in the shipbuilding industry and KPIs in the non-shipbuilding industry were analyzed and then KPIs were established for the shipbuilding PLM sector. Also, the KPI is classified into three categories. The project management viewpoint is applied to each vessel line, and the business unit viewpoint is divided into business units such as merchant ships or special ships, and the enterprise viewpoint is handled at the whole company level. Therefore, enterprise KPIs are large scale, enterprise wide and financial.

In this research, 5 kinds of KPIs from the viewpoint of enterprise management, 10 kinds of KPIs from the viewpoint of business unit, and five kinds of KPIs from the viewpoint of project management were derived.

The 5 KPIs from the perspective of enterprise management are cost reduction achievement rate, estimating accuracy rate, order margin ration, securing advanced technology / strengthening internal capacity, and reducing material costs. 
The 10 KPIs from the business unit point of view are the number of unique technologies, new CAD application rate, on-site feedback rate, design man-hour reduction achievement, accomplishment project performance, major equipment contracts, steel material achievement rate, design man-hour efficiency, steel scrap rate, internal information delay issue.

The 5 KPIs from the viewpoint of project management are the incidence rate of drawing change by the design cause in the production field, the compliance rate of the design process, the approval drawing acceptance rate, the ship owner/classification approval comment status, and the preceding outfitting ratio.

Fig. 3 shows the example of KPI description. It contains KPI code, name, definition, managing team, sector, formula, method of calculation, period, unit, target, data source and remarks.

\begin{tabular}{|c|c|c|c|c|c|}
\hline KPI Code & PM-002 & $\begin{array}{l}\text { Managing } \\
\text { Team }\end{array}$ & $\begin{array}{c}\text { Development } \\
\text { Team }\end{array}$ & Sector & Development \\
\hline KPI Name & \multicolumn{5}{|c|}{ Compliance Rate of the Design Process } \\
\hline KPI Definition & \multicolumn{5}{|c|}{ Percentage of Drawings created in Planned Schedule } \\
\hline Formula & \multicolumn{5}{|c|}{ Actual Number of Drawings / Planned Number of Drawings } \\
\hline $\begin{array}{l}\text { Method of } \\
\text { Calculation }\end{array}$ & Automatic & Period & Monthly & Unit & $\%$ \\
\hline Target & \multicolumn{5}{|c|}{$100 \%$} \\
\hline Data Source & \multicolumn{5}{|c|}{ PLM Project Management Module } \\
\hline Remarks & \multicolumn{5}{|c|}{ N/A } \\
\hline
\end{tabular}

Fig. 3. Example of KPI description

Fig. 4 shows the Shipbuilding PLM platform with big data analysis. Based on this platform, shipbuilding PLM system will be completed in connection with shipyard PLM service.

Through the KPI derived from this research, the risk assessment service is provided, the execution evaluation of the development work using the shipbuilding PLM is performed, and the decision making of the executives and the managers through the risk assessment is made possible. 


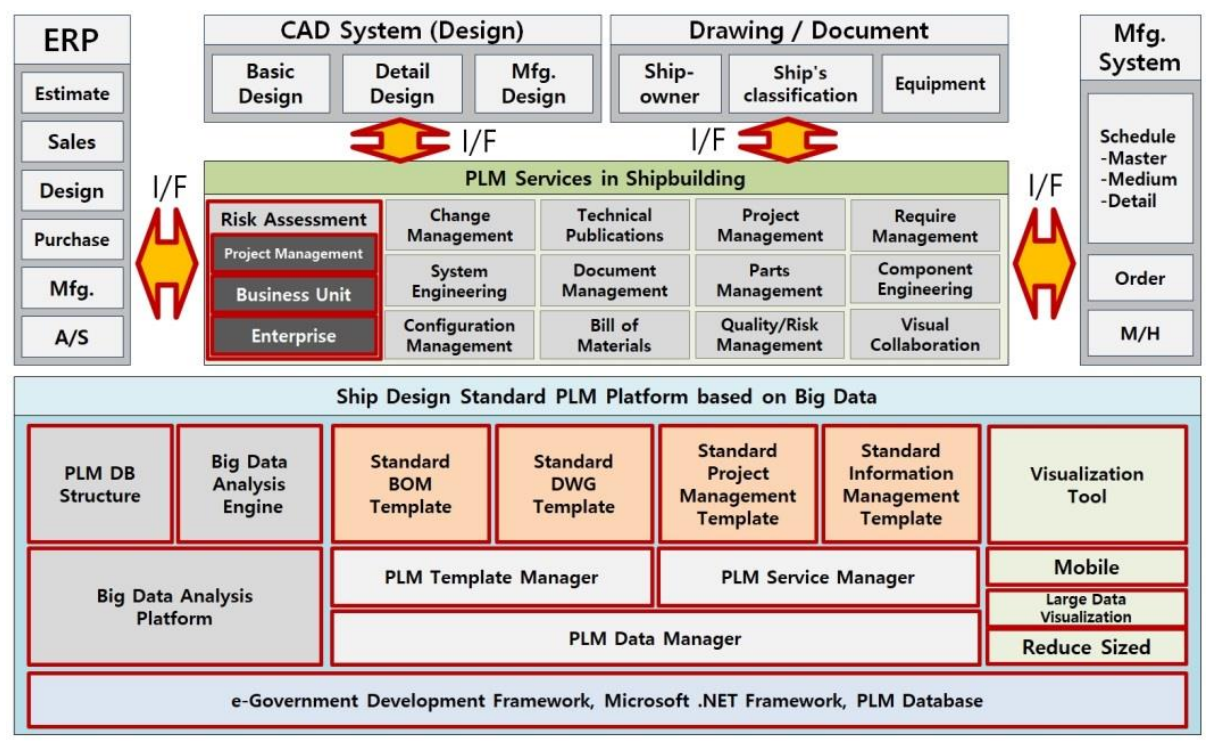

Fig. 4. Shipbuilding PLM platform with big data analysis

\section{Conclusion and Further Research}

In this paper, the methodology for establishing KPIs in the shipbuilding PLM is described.

In the future, product development performance and risk assessment will be linked to information systems that support monitoring, evaluation, and risk prediction of product development using KPIs of 3 viewpoints and design big data accumulated in PLM.

\section{Acknowledgement}

This work was supported by National IT Industry Promotion Agency(NIPA) grant funded by the Korea government(MSICT) (S1106-16-1025: Development of ship design standard PLM platform based on Big Data) and Y'sU(Youngsan university).

\section{$5 \quad$ References}

1. Drucker, P. F., 2006, The practice of management, Hankyung, Seoul, pp.181-204.

2. Issa, I. I., Pigosso, D. C. A., McAloone, T. C. and Rozenfeld, H., 2015, Leading productrelated environmental performance indicators: A selection guide and database, Journal of Cleaner Production,108 (Part A), pp.321-330. https://doi.org/10.1016/j.jclepro.2015.06. 088

3. Rodrigues, V. P., Pigosso, D. C. A. and McAloone, T. C., 2016, Process-related key performance indicators for measuring sustainability performance of ecodesign implementation 
into product development, Journal of Cleaner Production, 139, pp.416-428. https://doi.org/10.1016/j.jclepro.2016.08.046

4. Alemanni, M., Alessia, G., Tornincasa, S. and Vezzetti, E., 2008, Key performance indicators for PLM benefits evaluation: The Alcatel Alenia Space case study, Computers in Industry, 59(8), pp.833-841. https://doi.org/10.1016/j.compind.2008.06.003

5. Myung, S., 2008, Implementation process of enterprise PLM system, Proceedings of International Conference on Product Lifecycle Management 2008.

6. Folan, P., Browne, J., 2005, A review of performance measurement: Towards performance management, Computers in Industry, 56(7), pp.663-680. https://doi.org/10.1016/ j.compind.2005.03.001 